\title{
Paisajes duales en la Galicia tradicional: estructura, génesis y transformación ${ }^{1}$
}

\author{
Dual Landscapes in Traditional Galicia: \\ Structure, Genesis, and Transformation
}

\author{
Marco V. García Quintela \\ Departamento de Historia 1, Facultade de Xeografía e Historia. \\ Universidade de Santiago de Compostela
}

\section{RESUMEN}

Se estudian dos parroquias del interior de Galicia analizando información arqueológica, etnohistórica y etnográfica con una metodología estructural aplicada al examen de los paisajes. Los rasgos identificados en esas parroquias sugieren que se pueden definir como "paisajes duales" anclados o construidos sobre restos de la Edad del Hierro que, a su vez, nos invitan a preguntarnos sobre su génesis. Se señala la existencia de un dualismo dialéctico propio de un trasfondo cultural céltico, atestiguado en la protohistoria regional, y que se correspondería con esos "paisajes duales" identificados. Sin embargo, se desestima la pertinencia del concepto de "supervivencia", pues tanto el patrón de poblamiento como la religión cambian profundamente al principio de la Edad Media. Así, aunque la estructura dual identificada hunde sus raíces en la Edad del Hierro la situación observable responde a las vivencias de los campesinos cristianos que les dieron sentido durante los siglos posteriores.

Palabras clave: Historia de Galicia, Edad del Hierro, Edad Media, Cristianización, Paisajes sagrados, Mundo rural.

\section{SUMMARY}

We study the cultural landscapes of two parishes in the interior of Galicia using archaeological, ethno-historical and ethnographic data with a structural methodology. The features identified in these parishes suggest that they can be labeled as a "dual landscapes" anchored or built on the remains of the Iron Age period. This fact invites us to wonder about its genesis. We argue about the existence of a dialectical dualism of Celtic roots, and we remember that Celtic cultural and linguistic features are well attested in the region. Some kind of correspondence between the historical landscapes examined and the Celtic dualism is suggested. However, the relevance of the concept of "Survival" is dismissed as both the local settlement pattern and the religion change at the beginning of the Middle Ages. Thus, although the identified dual structure finds their roots

\footnotetext{
${ }^{1}$ Agradezco a J. C. Sánchez Pardo, A. González Ruibal y J. M. Andrade Cernadas su lectura de una primera versión del trabajo. C. H. Barba Seara, A. Fernández Fernández y D. Pérez López me han abierto sus intervenciones arqueológicas en Augas Santas y me han proporcionado informaciones todavía inéditas. Investigación subvencionada por Proyecto de la Xunta de Galicia: Arqueoloxía e relixión: da Idade do Ferro á Idade Media, 10PXIB210112PR.
} 
in the Iron Age, the observable social and religious reality belongs to the Christian peasants of later centuries.

Key words: History of Galicia, Iron Age, Middle Ages, Christianization, Sacred Landscapes, Rural World.

El paisaje es un objeto de estudio compartido por diversas disciplinas desde las cuales se han elaborado marcos teóricos de gran complejidad en los últimos años ${ }^{2}$. Se puede discutir si existe un espacio culturalmente neutro o vacío, por ejemplo en geometría, pero para aplicar el concepto de paisaje con propiedad es preciso que un segmento de la superficie de la tierra sea transformado por una mirada culturalmente condicionada que racionaliza y explica esa parte de la tierra, que decide qué acciones llevar a cabo allí, que selecciona qué conserva o qué destruye intencionadamente o, simplemente, abandona a la erosión del tiempo y de la atmósfera (Tuan 1997; Ingold 2000; Maderuelo 2005; Berque 2009). Partiendo de aquí la diferencia entre lo que es específico del estudio del paisaje y lo que es específico de otras formas de describir espacios es que el primero enfatiza la importancia del punto de vista cultural. De forma complementaria se constata que ese énfasis en la cultura del sujeto, del observador, ha ido de la mano con el predominio de metodologías de análisis de inspiración fenomenológica como las de Tuan, Ingold o Berque que hemos citado, por ejemplo.

En el presente ensayo partimos de la idea de paisaje como espacio construido por una mirada culturalmente condicionada elaborada por estos autores, pero nos distanciamos de ellos para subrayar el interés de observar los paisajes como expresión materializada de formas de pensamiento estructuradas (Criado 2012: 293-324). Esto es generadas y asentadas en las sociedades tradicionales en procesos cuyo sentido sólo es posible captar desde una perspectiva de larga duración que permite apreciar correctamente el contenido y la forma de esas transformaciones. No es casual que en su estudio definidor de la longue durée Braudel (1958: 731-732) señalara como ejemplos de la larga duración la "contrainte géographique" y "l'inmense domaine culturel".

Para abordar esta cuestión estudiaremos dos pequeñas parroquias del interior de Galicia, San Pedro de Cereixa, al sur de la provincia de Lugo, y Santa Mariña de Augas Santas, en el corazón de la provincia de Ourense (Fig. 1). En ambos casos hemos podido contar con información etnográfica y etnohistórica sobre cómo las comunidades campesinas que las habitan presentan sus marcos de referencia espaciales de tal manera que consienten su calificación como "paisajes duales". Esa presentación tiene una base cristiana evidente, pero el marco de relaciones espaciales definido es ajeno al cristianismo pues se apoya físicamente sobre restos arqueológicos de la Edad del Hierro. Se plantea, por lo tanto, la necesidad de rastrear su génesis "precristiana" caracterizando culturalmente esos precedentes y comprendiendo a micro escala cómo se cristianizan. Esto plantea la necesidad de una investigación histórico-arqueológica a escala local que no se ha llevado a cabo con la intensidad que sería necesaria, o solo parcialmente. Sin embargo, es posible sugerir una explicación en términos estructurales sobre la forma en que se produce la cristianización de los paisajes en un proceso de larga duración que, como decíamos más arriba, es siempre la forma más adecuada de comprender los paisajes.

\footnotetext{
${ }^{2}$ He propuesto revisiones sobre la cuestión en García (2011 y 2013).
} 


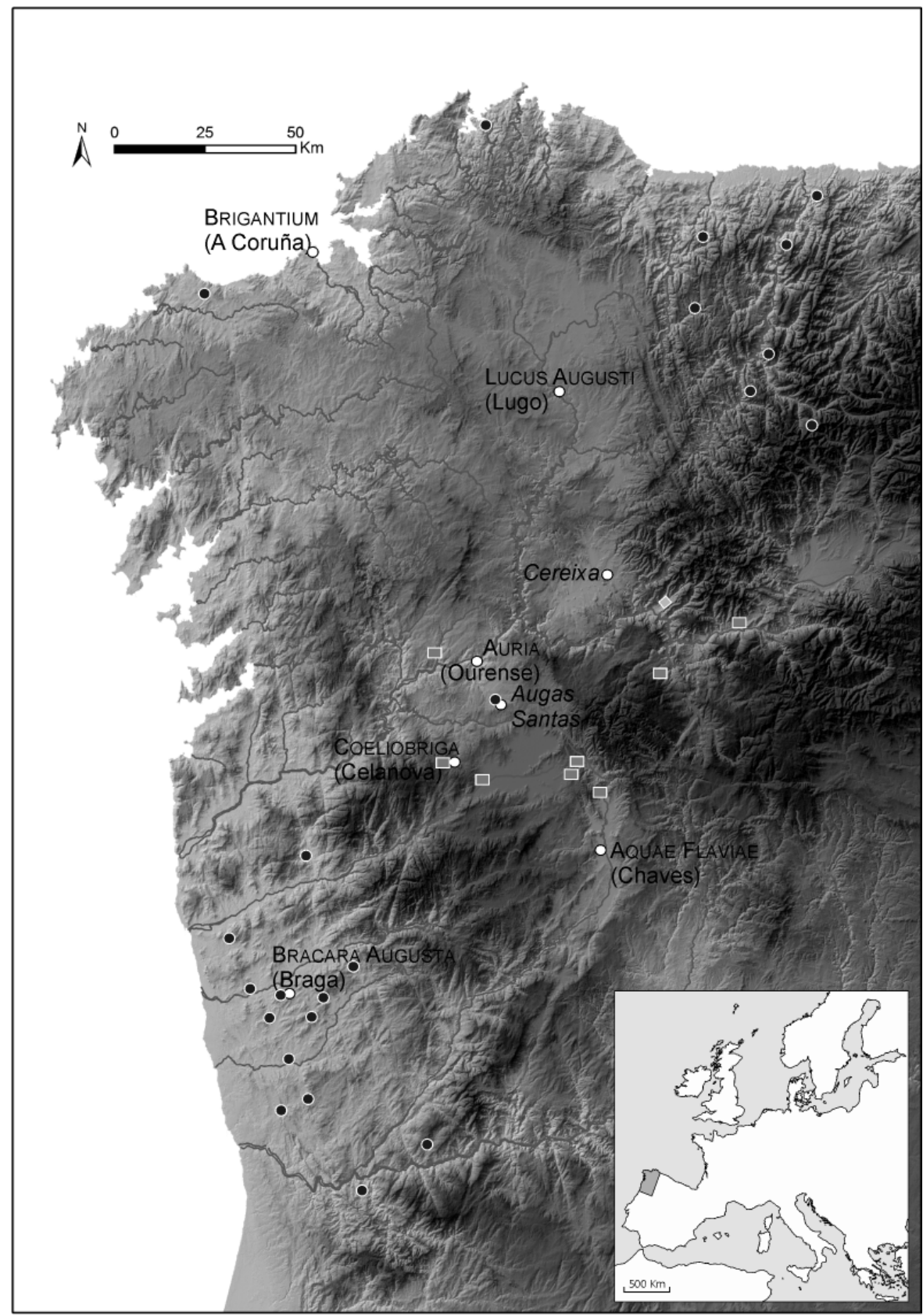

FIG. 1. - Lugares citados en el texto y otros importantes entre la Antigüedad y la Alta Edad Media. lugares estudiados NOMBRE ANTIGUO (nombre actual)

- saunas de la Edad del Hierro

topónimos en -briga de Ourense

Quiroga 


\section{EL PAISAJE DE DOS PARROQUIAS GALLEGAS}

Para empezar debemos fijar algunas nociones de cultura material y cronología.

Partimos de los castros, estructuras de habitación fortificadas de la Edad del Hierro que, con variantes regionales, ocuparon el NO peninsular. La conquista romana, finalizada el 26 a.C., no alteró esta situación. El abandono paulatino de los castros comienza en el siglo III y culmina a lo largo de la Alta Edad Media (Sánchez 2010). Sin embargo los castros como elementos conspicuos del paisaje permanecieron a lo largo de la historia como hitos físicos y lugar de residencia de seres maravillosos, mouros es el nombre más común, que protagonizan cuentos y leyendas (Arizaga y Ayán 2007). El dominio romano termina el año 411 d.C., cuando los invasores suevos se instalan en el sur de Gallaecia (Díaz 2011). Entonces la población campesina ocupa aldeas abiertas en los valles y el cristianismo se difunde desde las sedes episcopales urbanas por el medio rural.

Es posible que en las zonas afectadas por nuestro estudio el cristianismo sea anterior. En el sur de la provincia de Lugo el Parroquial suevo (lista de las diócesis y parroquias del reino suevo del siglo VI) cita la parroquia de "Carioca", la actual Quiroga cercana a Cereixa y lugar de donde procede el "crismón de Quiroga", testimonio de cristianización de inicios del siglo V (Delgado 1984; García García 2010). En el interior de la actual provincia de Ourense el siglo VII es la fecha de las primeras iglesias (Sánchez 2009: 436-437, 439), sin embargo Augas Santas, muy cerca de la sede diocesana de Auria (Ourense), junto a una antigua vía de tránsito, está presidida por el muy romanizado castro de Armea y su cristianización se puede considerar completa desde el siglo $\mathrm{VI}^{3}$.

Desde esas fechas se constituye el paisaje rural tradicional gallego vigente hasta la segunda mitad del siglo XX, cuando se produce el abandono de la población y su envejecimiento. Esto se debe a que ni las disputas jurisdiccionales de las edades Media y Moderna, ni la introducción de cultivos de América a partir del siglo XVII, modifican los patrones de habitación o las creencias.

\section{SAN PEDRO DE CEREIXA}

La información sobre Cereixa está recogida en un artículo de Ayán (2005) que presenta tres características: (1) explica la relación entre cultura material y sociedad en la larga duración; (2) considera la cultura material en su caracterización topográfica y topológica, definida por el saber tradicional; (3) Ayán tiene vínculos en la parroquia que le permitieron manejar una información etnográfica de calidad. Señalemos los elementos que invitan a definir ese paisaje como "dual".

\footnotetext{
${ }^{3}$ En el proyecto de investigación que financió este estudio hemos datado el Forno da Santa, sauna adyacente al castro de Armea (ver infra), con la tecnología de la Luminiscencia Ópticamente Estimulada aplicada a las argamasas utilizadas en las sucesivas reformas cristianas del edificio (responsables: Jorge Sanjurjo Sánchez, geólogo de la Universidade de A Coruña y Rebeca Blanco Rotea, arqueóloga, Universidade de Santiago). La muestra más antigua data, considerando el lugar de donde se extrajo, la primera remodelación del edifico el año 548 de nuestra era con un margen de error de más menos 45 años. Está en preparación la publicación completa de este estudio.
} 

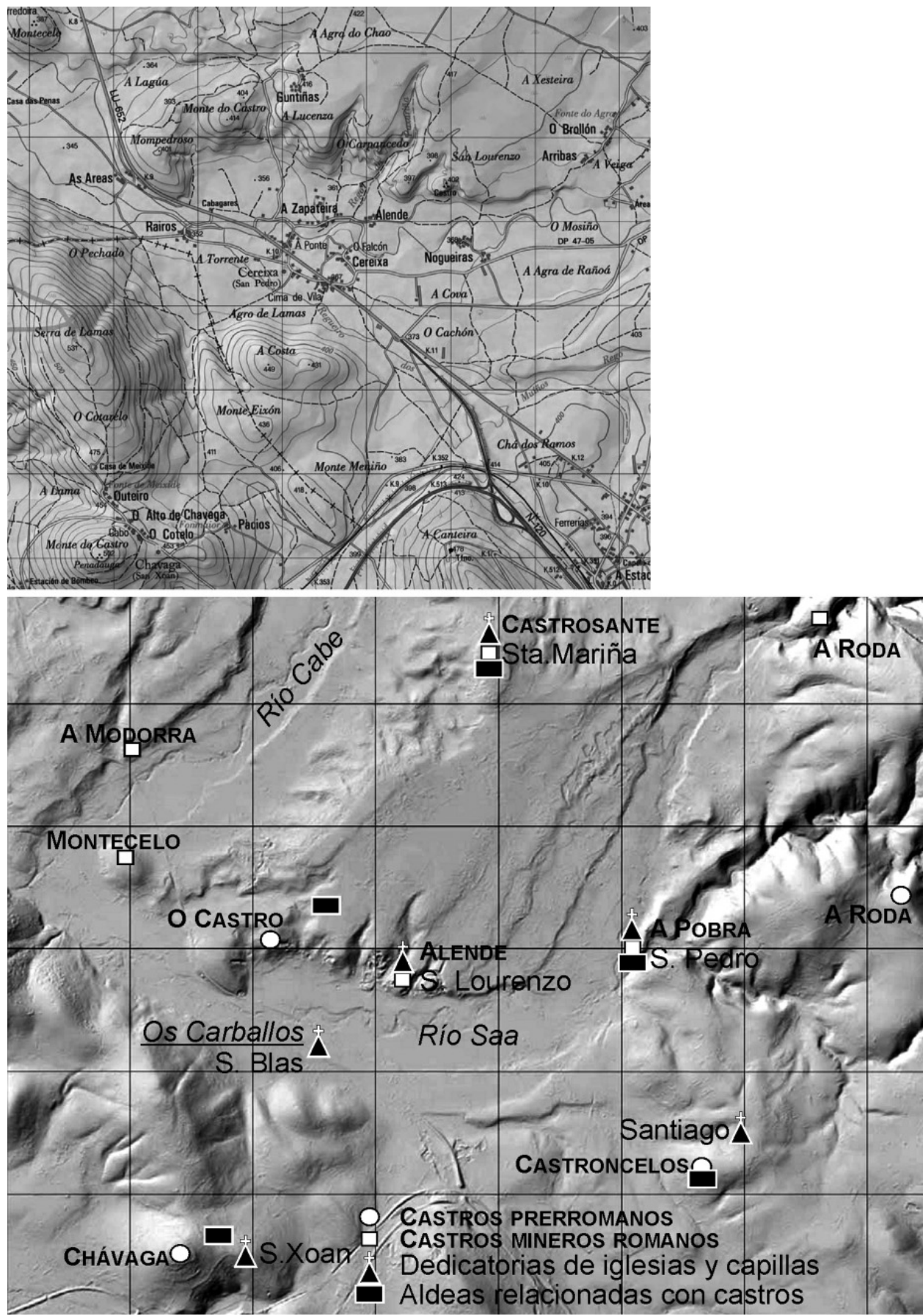

Fig. 2.-Topografía de San Pedro de Cereixa. Arriba: Mapa 1:21500.

Abajo: Mapa simbólico de la parroquia, de la Edad del Hierro a la cristianización. 
Cereixa es una parroquia del ayuntamiento de Pobra de Brollón al sur de la provincia de Lugo (Fig. 2). Su territorio sigue el curso bajo del río Saa, afluente del Cabe en torno al cual se sitúan las tierras destinadas a la agricultura (350 msnm). Hacia el oeste está limitada por pequeñas alturas entre los 450 y los $530 \mathrm{~m}$ y al norte del Saa los pequeños outeiros de Mompedroso, A Coroa/O Castro, A Lucenza, O Carpancedo y San Lourenzo marcan el límite entre el valle y la penillanura de Cha de Castrosante entre los ríos Saa y Cabe (420-440 m.). Según el censo de Madoz (1849: 327) la parroquia contaba con 321 almas. Ayán subraya cómo las historias que conforman el folclore y las prácticas sociales se asientan sobre huellas arqueológicas de diferentes épocas.

Destacan los castros dedicados a explotación aurífera en época romana. Aunque esta es una percepción de arqueólogos, ajena a la comunidad campesina que no distingue entre las épocas y funciones de unos castros indistintamente reconocidos como hitos del paisaje.

Las aldeas se ubican en relación con los castros: en sus laderas (cuatro casos) o a sus pies (otros cuatro), y las construcciones religiosas dedicadas a mártires se levantan, también, en las cimas de los castros (cuatro) o a sus pies (cuatro). Iglesias y aldeas en las cimas coinciden en tres ocasiones y otras tres veces a pie de castro. Difieren los dos castros que dominan el norte del valle del Saa: la aldea de Guntiñas al pie de O Castro carece de advocación religiosa y sobre la cima del castro de Alende se levanta la capilla de San Lorenzo, sin hábitat. Esta realidad estructura el paisaje desde que la población se asienta en el valle. La documentación para las épocas medieval y moderna no altera esta pauta de ocupación. A partir de esta realidad se configura lo que Ayán denomina la "cartografía mítica de la parroquia"; nosotros preferimos el término "topología", con dos enclaves destacados.

Por un lado, en la aldea más importante situada en un paso sobre el río Saa (A Ponte) está un centro simbólico doble: la iglesia parroquial dedicada a San Pedro y el área de Os Carballos. La iglesia actual se levantó en 1802 sobre otra probablemente románica. Os Carballos era un robledal centenario (talado en los años 80 del siglo pasado) adyacente a la iglesia y utilizado para reuniones y fiestas, sobre todo la Noite dos Cepos celebrada la víspera de San Blas (3 de febrero), que consistía en el encendido de hogueras con tocones de árboles (cepos). Por otro lado, sobre las alturas que dominan el norte del valle destacan los castros de O Castro y Alende o San Lourenzo habitados por los mouros. También es importante su relación con las culebras que viven en sus pedregosas laderas meridionales y tienen propiedades medicinales. Estos dos puntos son objeto de tomas de posición por parte de las autoridades eclesiásticas y de los campesinos con énfasis o intereses diferenciados (la oposición directa entre campesinos e Iglesia es difícil de imaginar en la Galicia tradicional).

Esto se aprecia en las visitas parroquiales a Cereixa en donde Ayán ha recogido la descripción de los ritos celebrados en la iglesia con motivo de San Blas, sin mencionar la Noite dos Cepos. También se leen conminaciones a los curas para que luchen contra prácticas supersticiosas o ajenas a la ortodoxia. Es legítimo interpretar que el objetivo implícito de esas exhortaciones es la Noite dos Cepos evitándose el choque directo con prácticas comunitarias. Algo semejante aparece tras el estatus diferente de los santos representados en la iglesia parroquial, articulado en torno a tres argumentos: (1) la historicidad de los cultos cristianos del panteón local, destacando 
(2) los difundidos tras el concilio de Trento (Nosa Señora do Rosario o Santa Bárbara), y (3) la querencia de los campesinos por San Blas y San Lourenzo como protagonistas del espacio y del tiempo locales. Detengámonos en éstos últimos.

Ambos son mártires y configuran el horizonte de la cristianización más antigua de la comarca, al igual que ocurre en otros lugares, como explica Brown (1983). San Blas era obispo de Sebaste en Armenia (siglo IV) y San Lorenzo, muerto el 10 de agosto del año 258, es un venerado mártir. En Cereixa cada uno tiene formas específicas de culto. El culto a San Blas era el más importante, según un anciano de 90 años:

o San Blas era a festa propia, de sempre, era o Patrón xa en tempos antiguos. Deixouse de facer cando eu era pequeno. Era moi nombrada e viñan ofrecidos e todo doutras parroquias. Despois íbase a Mosteiro, á festa do San BIas. Había a costumbre de queimar os Cepos de carballo seco nos Carballos, a noite de véspora. Para apañar os cepos iban os homes con carros a Pinel e a Brence, e de paso enchíanse os carros de nabos e outras causas. Facíase unha pota de arroz e xa había festa. Érache boa festa porque se comía o da matanza, en troques no Rosario comprábase todo fóra. Índa recordo a copIa que se lle cantaba:
Meu Santo San BIas de Viana.
feito de pau de amieiro, irmao das miñas angrellas, criado no meu ribeiro (Ayán 2005: 157) .

Por su parte San Lorenzo, aunque tiene una imagen en la iglesia, recibe un culto especial en el castro de Alende. Según cuenta el abuelo de Ayán (2005: 161):

o San Lourenzo trouxérono os curas dalí. do castro. para a iglesia. pero o santo marchaba e iba po castro. quería seguir alí, así que se lie fixo outra capela no castro. A miña abuela contaba das rogativas que se facían cando había sequia: que un ano que non chovera nada fórase en procesión desde o castro hasta o río e ó molla-lo santo no río comezou a chover, salvando as colleitas. Eu xa non a recordo, a capela. Que índa se verán aínda os muros. A pedra levouse dalí para as casas da Lendes.

Es oportuno indicar que San Lorenzo, el santo quemado en la parrilla, fue reinterpretado por la tradición popular gallega como un santo hidróforo (Bouza 1982: 128-33, 236-9) en un relevante juego de oposiciones. Ayán (2005: 162) termina su

\footnotetext{
${ }^{4}$ "San Blas era la fiesta propia, de siempre, ya era el patrón en los tiempos antiguos. Se dejó de celebrar cuando era pequeño. Era una fiesta muy famosa y venían fieles y otros de otras parroquias. Después se iba a Mosteiro, a la fiesta de San Blas. Se tenía por costumbre quemar los Tocones de roble seco en os Carballos, la noche antes. Para recoger los tocones iban los hombres con carros a Pinel y a Brence, y de paso se llenaban los carros con nabos y otras cosas. Se hacía una pota de arroz y ya había fiesta. Era una buena fiesta porque se comía lo de la matanza, sin embargo en la fiesta del Rosario se compraba todo afuera. Todavía recuerdo la copla que se le cantaba: 'Mi Santo San Blas de Viana / hecho de palo de aliso / hermano de mis parrillas / criado en mi orilla'".

5 "A San Lorenzo lo trajeron los curas de allí, del castro, para la iglesia. Pero el santo regresaba al castro, quería seguir allí, así que se le hizo otra capilla en el castro. Mi abuela me contaba las rogativas que se hacían cuando había sequía: que un año que no había llovido nada se fue en procesión desde el castro hasta el río y al mojar al santo en el río comenzó a llover salvando las cosechas. Yo ya no recuerdo la capilla de la que todavía se ven los muros. Sus piedras se llevaron de allí para construir las casas de Alende».
} 
análisis resumiendo la estructura mítica de la parroquia que presento con algunas variantes (tabla 1). Pasemos al segundo caso.

TABLA 1.-Estructura mítica de la parroquia de Cereixa

\begin{tabular}{|l|l|l|l|l|l|}
\hline advocación & culto & fecha & sitio & posición & elemento \\
\hline San Blas & mártir & 3 febr. & Carballos & central & fuego \\
\hline San Pedro & apóstol & 29 jun. & Iglesia & Central & \\
\hline San Lorenzo & mártir & 10 ago. & Castro & Periférica & agua \\
\hline Virgen Rosario & Trento & 7 oct. & Iglesia & Central & \\
\hline
\end{tabular}

\section{SANTA MARIÑa DE AUgas SANTAS}

Es una parroquia del ayuntamiento de Allariz, en el centro de la provincia de Ourense. Son bien conocidos sus importantes restos arqueológicos y la antigua devoción a la santa que le da nombre (Fariña 2002). El culto ha conformado la arquitectura de la aldea destacando el templo parroquial románico junto con otros enclaves arqueológicos de la Edad del Hierro y romanos integrados en la hagiografía de Mariña.

El territorio de la parroquia de Santa Mariña de Augas Santas (Fig. 3) se centra en el monte de Os Canteiros, que conforma el extremo occidental de un cordal montañoso denominado Lombas de Santa Mariña, con alturas que no llegan a los $700 \mathrm{~m}$. Hacia el norte la parroquia se prolonga hacia el valle de A Rabeda (400 m) y hacia el sur incluye todo el monte de Os Canteiros. Según Madoz (1848: 127) la parroquia contaba con 692 almas.

La leyenda Santa Mariña se adhiere al territorio como un manto de narrativa que lo cubre y le da sentido 6 . Esta unión entre lugares y episodios "mariñianos" tiene la facultad de convertir esos lugares en otros tantos loci memoriae (Yates 1999) contribuyendo a la estabilidad de la leyenda.

El mejor testimonio es obra de Juan Muñoz de la Cueva (1660-1728), obispo de Ourense desde 1717 hasta su muerte, quien publicó en los años 1719 y 1726 dos libros con el mismo texto. El primero está dedicado a Santa Mariña (Muñoz 1719), y el segundo, sobre la catedral de Ourense, incluye el texto del anterior. Muñoz pasó los veranos de 1718 y 1719 en Augas Santas documentándose para su obra, examinando los monumentos (Muñoz 1719: 12) y recurriendo a "información auténtica" que un cura de Santa Mariña recibió en 1592 "de siete testigos muy ancianos" (Muñoz 1719: 13). Otros testimonios atestiguan la estabilidad de estos relatos.

Benito de la Cueva († 1649), historiador del monasterio de San Salvador de Celanova, presenta la historia de la Santa en términos semejantes (de la Cueva 1991: 283-287), así como otros testimonios del martirio ocurrido en el Forno de la Santa (Molina 1551: p./f. 23 /VIII; Morales 1574: 384-385). En la actualidad los vecinos co-

\footnotetext{
${ }^{6}$ Evoquemos las relaciones de Atenea con Atenas (Loraux 1984) o de Rómulo con Roma (Briquel 1980).
} 


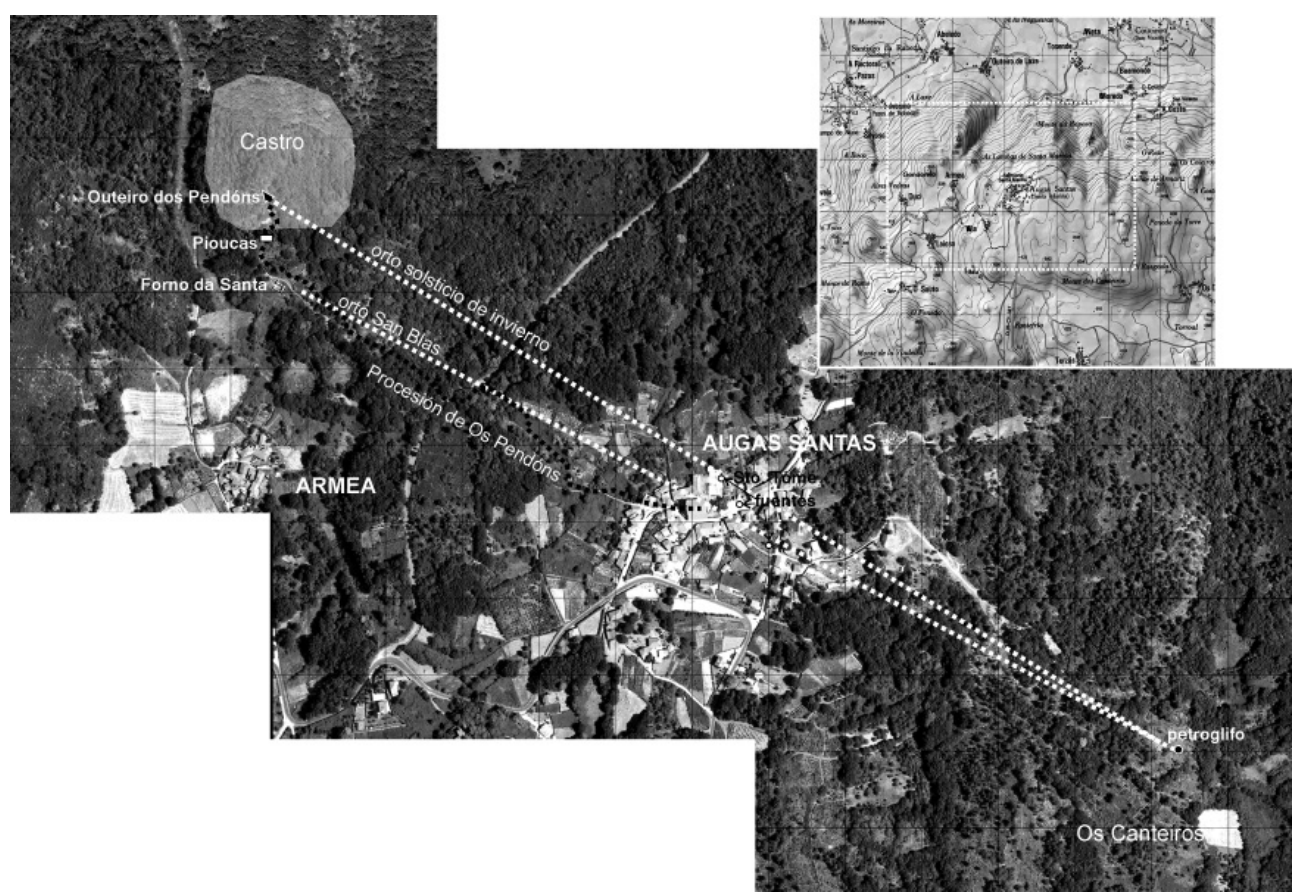

FIg. 3.-Topografía (arriba) y "topología" de Santa Mariña de Augas Santas con los elementos arqueológicos de la Edad del Hierro.

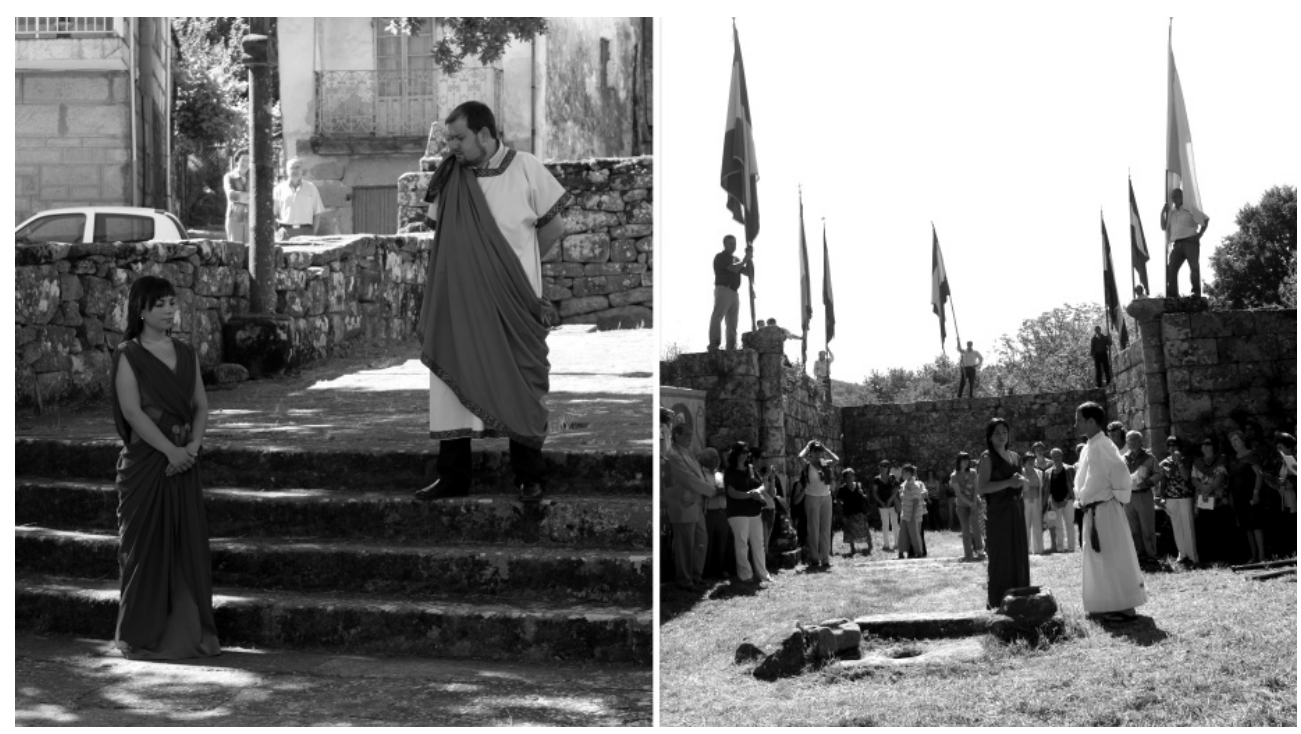

Fig. 4.-Dos momentos de la representación del martirio de Santa Mariña el día de la Ascensión de 2011. Izquierda en el patio de la iglesia de la aldea, derecha, en la nave de la Basílica de la Ascensión, en el centro el agujero que comunica con el Forno da Santa que configura la cripta. 
nocen esos relatos, cuentan milagros protagonizados por seres queridos y el párroco promueve la representación de algunos episodios de la historia de Santa Mariña en los lugares en que tuvieron lugar durante las fiestas de la Ascensión y de Santa Mariña (Fig. 4).

Desde que se formó la leyenda, coincidiendo con la cristianización de la zona, parece haberse establecido una dialéctica constante entre el folclore local sobre restos de la Edad del Hierro y otros hitos del paisaje (rocas, fuentes, árboles) y Santa Mariña, conservándose seguidamente esa tradición debido a la función del púlpito como vía de comunicación entre el saber de la comunidad campesina sobre su entorno y la cultura de la Iglesia. Sin que sea posible discernir dónde empieza uno y dónde termina otro.

La relación entre Santa Mariña y el territorio de Augas Santas da pie a aproximaciones diversas (Barandela y Lorenzo 2011; García y Seoane 2011) y están en curso intervenciones arqueológicas en tres lugares diferentes. Presentaremos una aproximación panorámica a la relación entre el territorio, la hagiografía de Mariña y otros cultos. Destacan tres puntos en la ladera de Os Canteiros.

1. La cima del Monte es el punto más alto de las Lombas de Santa Mariña (669 $\mathrm{m})$. Es una zona de cultivo de cereales abandonada. Rodeado por un muro circular el petroglifo de A Vacariza está grabado en el extremo de una gran roca plana. El resto de la roca, sin grabados, se usaba como eira de mallar y para acelerar la maduración del trigo. La tradición interpreta los grabados como la huella de un milagro: un cristiano esclavo de los moros consiguió la libertad gracias a Mariña, dos formas oblongas son las huellas de sus pies, formas semicirculares las herraduras del caballo en el que huyó y una serie de cazoletas la cadena que lo apresaba. Además ocho cruces se grabaron con posterioridad a la cuidada descripción de Muñoz de la Cueva, pues no las menciona. Flanquean los grabados tres zonas donde la roca está erosionada por la acción de fuegos intensos e intencionados (García y Seoane 2011). Esta afirmación se basa en que los grabados no están afectados, en la escasez de humus que impide crecer los árboles y hace necesario llevar el combustible y en el conocimiento del efecto de fuegos intensos sobre el granito (Seoane 2011).

2. Sobre la ladera, a un $\mathrm{km}$ hacia el oeste está la aldea de Augas Santas con su iglesia y las tres fuentes que brotaron con cada bote de la cabeza de la santa decapitada. La más oriental ha perdido significado religioso. La segunda fuente, con un agua de gran calidad, mana a la sombra de dos grandes carballos. Está situada entre el patio de la iglesia y la plaza formada por las casas y junto al lavadero y el cementerio: es el centro de la aldea. La tercera es milagrosa, está dentro de una capilla dedicada a Santo Tomé y consiste en un pozo perfectamente construido (Fig. 5).

3. En el extremo occidental del monte dos Canteiros el terreno se eleva ligeramente antes de descender rápidamente hacia el oeste y el norte, allí se ubica el castro de Armea. Destacan tres estructuras de la Edad del Hierro reutilizadas por el cristianismo. (1) Bajando desde la aldea, en una vaguada antes de subir hacia el castro, está la Basílica de la Ascensión o Forno da Santa. Es una antigua sauna subterránea de la Edad del Hierro remodelada en la Edad Media como cripta para conmemorar que Santa Mariña sufrió allí el martirio por el fuego. Sobre el nivel 

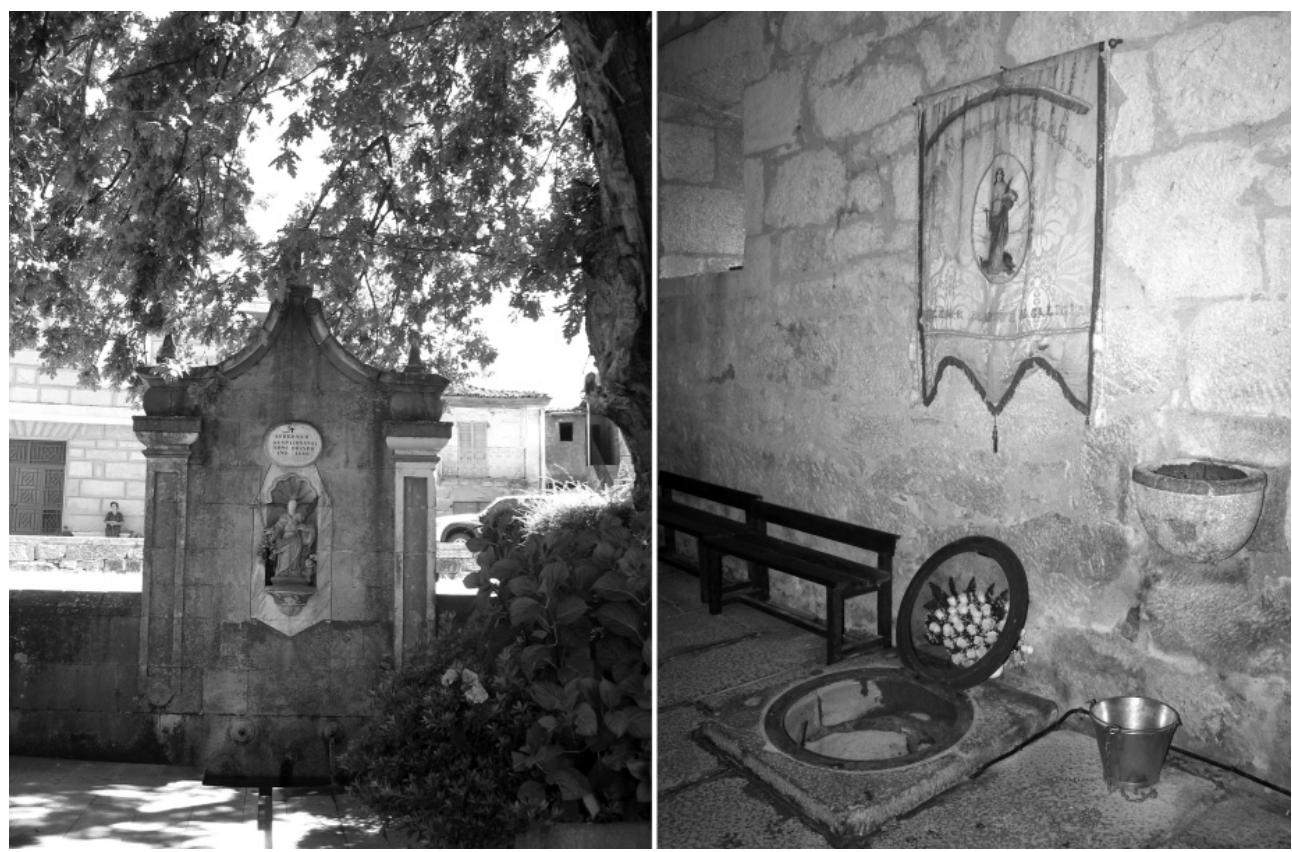

FIG. 5.- Izquierda, la fuente del centro de la aldea.

Derecha, la fuente en el interior de la capilla de Santo Tomé.

del suelo se inició la construcción de la inacabada Basílica, centrada en la salida de la chimenea del Forno. (2) Las Pioucas de Santa Mariña están al inicio de la subida hacia el castro. Son dos pilas situadas bajo un gran carballo y rodeadas por un muro. Cuando San Pedro rescató a Santa Mariña del Forno la refrescó en sus aguas. (3) Desde allí se asciende a la cima del castro llamada Outeiro dos Pendóns. Posiblemente era un lugar de interés ritual ya en la Edad del Hierro y en la tradición local atestiguada desde el siglo XVI (García y Seoane 2015). Es el destino de la procesión de Os Pendóns que consiste en llevar unos estandartes desde la iglesia parroquial hasta allí los días de la Ascensión y de Santa Mariña con paradas en la Basílica y en las Pioucas (Fig. 6).

\section{LA IDENTIFICACIÓN DE ESTRUCTURAS DUALES EN EL PAISAJE}

SAN PEDRO DE CEREIXA

No parece difícil distinguir, a la luz de la tabla 1, la diferencia entre una estructura fundamental de organización del tiempo, del espacio y, en general, de los cuadros simbólicos básicos de la comunidad, y sus ampliaciones. Esto se hace evidente si constatamos que los cultos de San Blas y San Lourenzo conforman una serie de dicotomías (tabla 2) que comentamos. 

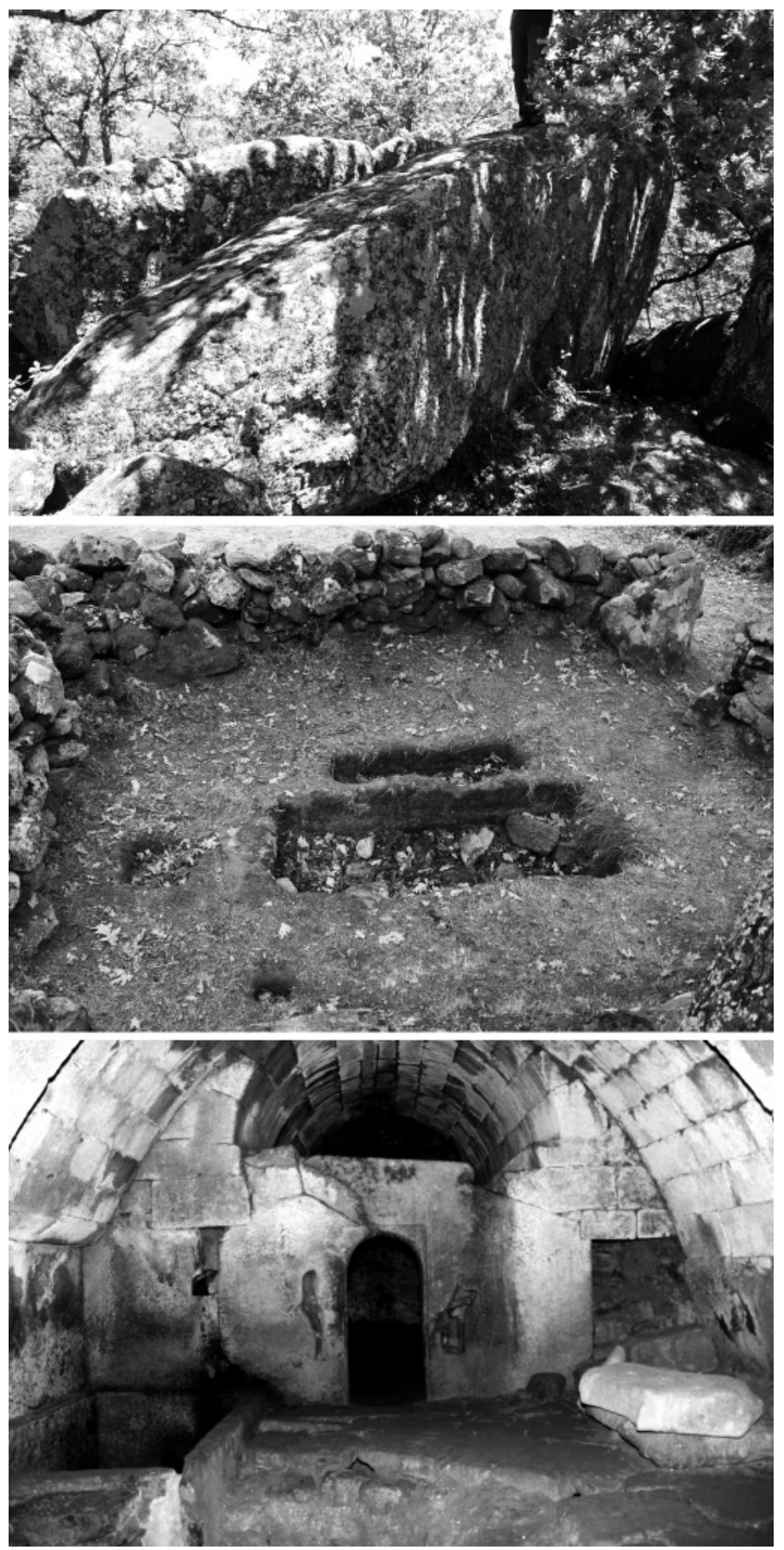

Fig. 6.-Elementos simbólicos del castro de Armea. Arriba, Outeiro dos Pendóns. Centro, Pioucas de Santa Mariña. Abajo, Forno da Santa. 
TABLA 2.-San Blas y San Lourenzo en Cereixa

\begin{tabular}{|l|l|l|}
\hline santos & San Blas & San Lourenzo \\
\hline espacio & centro y abajo & periferia y arriba \\
\hline tiempo & 3 febrero: mitad invierno & 10 agosto: mitad verano \\
\hline elementos & fuego y roble & agua y roca \\
\hline desplazamiento & sube (fuego, árbol) & baja (baño en río, piedra usada en valle) \\
\hline habitantes & campesinos & mouros \\
\hline
\end{tabular}

1. En el plano espacial es pertinente, junto con la dicotomía centro/periferia, la dicotomía abajo/arriba, pues Os Carballos y el culto de San Blas se sitúan en el valle y el culto a San Lourenzo en el castro homónimo sobre una altura.

2. En el plano temporal los santos dividen el año en dos mitades casi exactas y los ritos asociados de fuego en invierno y agua en verano evocan la estación opuesta.

3. La relación de San Blas con la madera y los robles es clara. La de San Lorenzo con la roca está en las estructuras pétreas del castro, en las culebras de las rocas de su ladera o en las piedras de la capilla reutilizadas en la aldea de Alende.

4. Correlativa con la contraposición entre elementos y estaciones está la contraposición entre localizaciones y desplazamientos, de modo que cada posición evoca a su contraria en dos pares solidarios, pues el fuego sube en forma de llamas o humo, mientras que el agua baja como ríos o lluvia (tabla 3).

\section{TABLA 3.-Estructura dual del paisaje de Cereixa}

\begin{tabular}{|c|}
\hline fuego:invierno :: agua:verano \\
\hline bajo (valle):subida :: alto (cima):bajada \\
\hline
\end{tabular}

Este análisis se puede prolongar con la relación entre vaca y culebra, recurrente en el folclore gallego (Criado 1986). Ayán (2005: 149) recoge una noticia sobre O Castro según la cual "no Castro téñense visto cobras mamando dos tetos dunha vaca". De esta forma se produce en ese espacio liminal la unión entre la vaca, el animal más cercano al campesino, y la culebra, el más alejado. Algo semejante se produce con la presencia de San Lourenzo en el castro homónimo también habitado por mouros (Ayán 2005: 149150). Es decir, la vaca o San Lourenzo son como los centinelas de la cultura del valle en las atalayas/castros situados en la frontera con los espacios poblados por animales salvajes o seres del otro mundo. Es relevante que el rito veraniego consistente en bajar la estatua de San Lourenzo al río para provocar la lluvia invierta espacialmente la unión de contrarios expresada por la imagen de la vaca que sube al castro para amamantar una culebra estando en juego los líquidos, leche y agua, necesarios para la vida.

Los otros cultos se acumulan sobre esta estructura sin alterarla hasta que se desvanece a lo largo del siglo XX. Es preciso, por tanto, matizar. Blas, Pedro, Lourenzo 
o la Virgen son objeto de culto por igual, pero varían los protagonistas destacando la dimensión "popular" de San Blas y San Lourenzo y la dimensión "oficial" de los restantes cultos.

\section{Santa Mariña de Augas Santas}

La dualidad del paisaje de Augas Santas es menos evidente porque son relevantes tres puntos: la cima con su petroglifo, la aldea con sus fuentes a media ladera y el castro en la parte baja. Parece legítimo, sin embargo, agrupar las fuentes y el petroglifo arriba y el entorno del castro abajo. Esta bipartición se justifica por las orientaciones solares de los monumentos en torno al castro. En el presente argumento consideramos las alineaciones solares como realidades que configuran el paisaje local y que, como tales, son un testimonio equivalente a una observación arqueológica o a una noticia hagiográfica o etnográfica (García y González 2009).

En primer lugar, el Outeiro dos Pendóns está coronado por una gran roca natural partida en tres grandes bloques orientados hacia el naciente del sol, el solsticio de invierno, cuyo disco se eleva por el horizonte sobre la cima de Os Canteiros. El interés de esta observación se aprecia por su cristianización a través del culto a Santo Tomé (21 de diciembre) que alberga la fuente más santa. En segundo lugar el Forno da Santa mantiene, pese a sus remodelaciones, una orientación hacia los primeros días de febrero, y un culto local secundario es el de San Blas (3 de febrero).

Por lo tanto el petroglifo de A Vacariza y las fuentes santas constituyen la mitad superior de la estructura dual y el entorno del castro con el Forno da Santa y las Pioucas, la mitad inferior. Otros elementos corroboran esta apreciación.

Arriba domina el agua de las fuentes, aunque el fuego está presente en el petroglifo de Vacariza. Abajo predomina el fuego del Forno, aunque el agua está presente en las Pioucas. Arriba dominan las fechas invernales de Santo Tomé y de San Blas. Abajo importan las fechas de primavera (Ascensión) y verano (San Pedro, 29 de junio). No consideramos a Santa Mariña (18 de julio) debido a su omnipresencia. Sin embargo, la Basílica de la Ascensión presenta una orientación solar doble: la cripta hacia el naciente el 3 de febrero y la nave exterior hacia el poniente el 18 de julio, pero como está inacabada es imposible conocer el reflejo de este rasgo en la arquitectura del edificio. En la tabla 4 formalizamos este paisaje.

TABLa 3.-Estructura dual del paisaje de Augas Santas

\begin{tabular}{|c|c|}
\hline (BAJO/VERANO) & (ALTO/INVIERNO) \\
\hline agua (marginal) : fuego (axial) :: fuego (marginal) : agua (axial) \\
\hline
\end{tabular}

No es necesario subrayar las semejanzas entre las tablas 3 y 4 que presentan las observaciones efectuadas como variantes de una estructura que configura sendos paisajes cristianos fundados sobre restos arqueológicos de la Edad del Hierro. Esto nos lleva a interrogarnos sobre la génesis de estos paisajes. 


\section{ARQUEOLOGÍAS DE LOS PAISAJES DUALES}

Usamos "arqueología" en el sentido foucaultiano como análisis de las capas de sentido que configuran los enunciados del discurso (Foucault 1970). En nuestro argumento esos enunciados son los formulados por las comunidades campesinas para explicar el sentido de los lugares que habitan y que coexisten e interactúan con los enunciados formulados por la cultura de la Iglesia con sus mecanismos centralizadores del culto, el dogma y la disciplina en las costumbres. Pero también usamos "arqueología" como disciplina histórica que estudia las condiciones materiales de existencia de las sociedades pretéritas.

El recurso a ambas "arqueologías" deriva de la evaluación de los elementos relevantes de nuestro estudio. Ello se debe a que las narrativas que dan sentido a los paisajes están ancladas en lugares relevantes para una arqueología como estudio de las formas materiales. De esta forma nos encontramos ante una dialéctica entre la arqueología de las narrativas y la arqueología de los objetos y su localización en el espacio como las dos caras de una misma moneda. Intentaremos mostrar cómo se presenta esto.

\section{SAN PEDRO DE CEREIXA}

La relación entre ambas "arqueologías" en el castro de San Lourenzo es muy clara. El castro se estudia desde la arqueología como disciplina al mismo tiempo que es la sede de relatos y de prácticas sociales, propios de una cristianización antigua y popular que convierte al lugar en hito estructurador del paisaje. Esto es más complejo en Os Carballos donde, no obstante, es posible identificar rasgos materiales propios de los lugares de celebración protohistóricos.

1. El roble tiene un gran valor simbólico en la tradición indo-europea y celta 7 . En España hay lugares en donde conserva a través de los siglos un gran valor simbólico, como el Carbayón de Oviedo y, sobre todo, los robles de significación jurídica de Vizcaya (García y Delpech 2013).

2. Os Carballos está en la confluencia entre el río Saa y el Regueiro dos Muiños. Las confluencias (condate) son lugares de reunión en el mundo galo (Delamarre 2003: 123-124). Se ha sugerido que en Gallaecia el dios prerromano Cossue diviniza este hecho (Prósper 2002: 204-224) y es posible que algunos condados de la toponimia gallega deriven de un "condate" prerromano (Moralejo 2008: 141).

3. Muchos lugares de reunión precristianos carecen de estructuras materiales, las tienen efímeras, o presentan temporalidades diferentes entre las materializaciones y las prácticas. Podemos evocar en Irlanda los lugares de celebración de Lugnasad o los royal sites (MacNeill 1962; FitzPatrick 2004; Schot 2006) y situaciones análogas en la Inglaterra altomedieval (Blair 2005: 182-245 y 475-477). En la Galicia actual muchas romerías y fiestas se celebran en lugares sin es-

\footnotetext{
${ }^{7}$ Bader (1966) en general. Para los celtas, Máximo de Tiro, Disertaciones 2.8; Estrabón, Geografía XII, 5, 1; Plinio, Historia Natural, XVI, 95. En Irlanda el nombre de Kildare, el santuario de Brigit, deriva de Cill Dara, "celda del roble", pues se levantó bajo un roble (Sherlock 1896: 16, 19).
} 
tructuras permanentes. Ciertamente es peligroso argumentar a partir de una ausencia de evidencia, pero también sabemos que es usual en ciertos lugares de reunión tanto la ausencia de restos como la presencia de restos acumulados a lo largo de épocas dispares.

A partir de aquí sugerimos que el uso comunitario de Os Carballos se remonta a la protohistoria. Desde entonces el lugar mantuvo vivo su rol simbólico recibiendo las resemantizaciones presentadas como resultado de una dialéctica entre el saber campesino y la presión de la Iglesia: el recurso a dos mártires paleocristianos con fiestas situadas en la mitad del invierno y en la mitad del verano revela la relación estrecha entre el paisaje arqueológico en sentido material y la semántica cristiana de ese paisaje.

\section{SANTA Mariña DE Augas SANTAS}

En Santa Mariña de Augas Santas todos los puntos de interés son restos arqueológicos de la Edad del Hierro reutilizados por la hagiografía de Mariña. La excepción relativa son las fuentes de la aldea, pero podemos postular que su significado religioso era anterior al cristianismo. Por lo tanto también en Augas Santas la disección de la materialidad de los restos del pasado y la aprehensión del paisaje local por la Santa constituyen dos aspectos inextricables de la conformación del paisaje. Destacamos dos temas para mostrarlo.

A gran escala el castro de Armea y el petroglifo de la cima de Os Canteiros muestran una relación dual entre castro y "Santuario" (a falta de palabra mejor) conforme a un modelo conocido (García y Santos 2008; De Bernardo y García 2008). Sobre esa estructura la leyenda de Santa Mariña relata una apoteosis definida por el camino ascendente desde el castro hasta la cima de Os Canteiros. Muñoz de la Cueva cuenta los pasos sucesivos: prisión en el castro, tormento en el Forno, decapitación que origina las fuentes, manifestación post mortem en la cima con el milagro de la liberación del esclavo. Esta "subida" narrada se desdobla en las relaciones solares indicadas y parcialmente, en dirección inversa, por el recorrido de la procesión de Os Pendóns (Fig. 7).

En el Forno da Santa ocurre un proceso similar. Recordemos que el monumento deriva de la remodelación de una sauna adyacente al castro, pero lo relevante ahora es que el tormento de Mariña allí situado reproduce el funcionamiento de las saunas de la Edad del Hierro. En ellas el agua se conduce hasta una entrada con pequeñas albercas, mientras que el fuego se enciende en una pieza construida en el fondo del edificio como una falsa cúpula subterránea. En una sala intermedia entre el agua externa y el fuego interno se produce el vapor de la sauna. Pues bien, Mariña es literalmente el "agua" que, sometida al fuego, produce vapor. Bajo ese estado, San Pedro la saca del Forno y la devuelve al estado líquido en As Pioucas. El funcionamiento material de la sauna protohistórica y el episodio hagiográfico se corresponden, por lo tanto, de una forma extraordinariamente precisa.

Constatada la base material de las estructuras identificadas en entes físicos de la Edad del Hierro debemos preguntarnos si también había concepciones ideológicas duales que estructuraban esos paisajes en la protohistoria. 

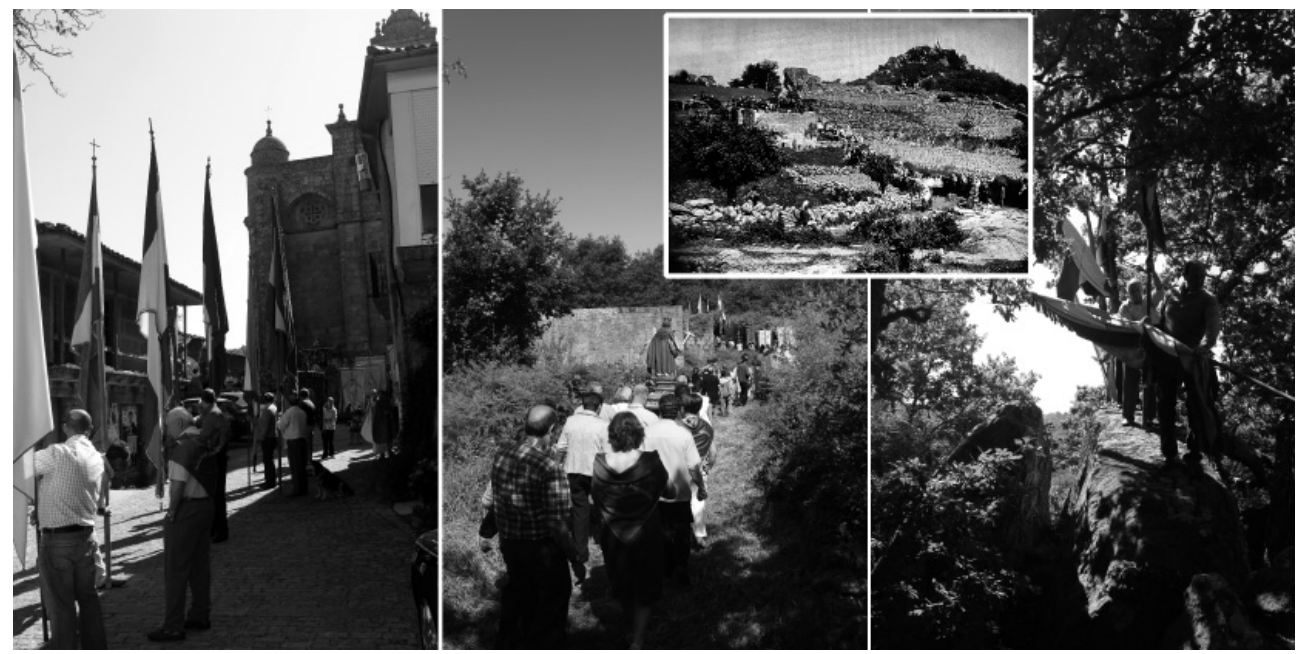

Fig. 7.-La procesión dos Pendóns. Izq. salida desde la iglesia parroquial. Centro, llegada a la Basílica de la Ascensión. Dcha. Los Pendóns se retiran del Outeiro dos Pendóns. En el recuadro fotografía de los años 20, sin árboles, donde se aprecia la procesión, la Basílica y el castro cuya cima es el Outeiro dos Pendóns, las Pioucas están tras la gran roca (Pedra da Moura) que se recorta en el horizonte a la izquierda del castro.

\section{DUALISMO Y TRADICIÓN CELTA}

Para responder tropezamos con un obstáculo conceptual que planteamos como pregunta ¿dónde situamos el punto de inflexión entre una serie de observaciones a partir de las cuales podemos definir una teoría que les da sentido y la existencia de una teoría aceptada por una comunidad erudita, a la se pueden añadir otras observaciones o casos que la completan? Dicho de otra forma. Debemos limitarnos a constatar la existencia de los paisajes duales observados considerando sus adherencias materiales un mero accidente o estas adherencias materiales nos exigen buscar una explicación de su presencia en la estructura en identidades culturales protohistóricas.

El problema es que la idea de un dualismo ideológico o cultural celta no forma parte de la communis opinio entre historiadores de las religiones o arqueólogos de la Edad del Hierro. Dificulta la cuestión la inexistencia de corpus documental para el conocimiento de los celtas claramente constituido, lo que da pie a discusiones (Collis 2003; Sterckx 2009). Sin embargo existen observaciones que sustentan la existencia de un dualismo celta aunque todavía están poco difundidas. Como nuestro argumento apunta en esa dirección es necesario presentarlas. Recordemos previamente los testimonios sobre la etnicidad celta de la Gallaecia prerromana.

Textos antiguos de Estrabón, Plinio y Pomponio Mela, y algunos epitafios latinos presentan a sus pobladores como "celtas" (González 2011: 119, 121). Lingüísticamente el NO de la Península Ibérica está en el área de los topónimos terminados en -briga, "altura", "fortaleza" en lengua celta, que establece la geografía del uso de las lenguas celtas, en concreto ocho de los 78 topónimos conocidos en la Península están en la 
provincia de Ourense (Guerra 2005: 812-817; García Alonso 2006; Luján 2009). Pero el celta coexiste con el lusitano, idioma también indoeuropeo, discutiendo los especialistas los detalles de esa coexistencia ${ }^{8}$. Veamos ahora algunos elementos de dualismo celta.

El más claro es el calendario, conocido por la lengua, la etnografía y el calendario de Coligny. Es un calendario luni-solar, los meses lunares duran 30 días y 29 días alternativamente y se dividen en dos mitades de 15+15 días o 15+14 días. Las primeras mitades, centradas en la luna llena, son "claras" y las segundas "Oscuras", pues pivotan sobre la luna nueva. Para acomodar esta secuencia con el ciclo solar se introduce un mes de 30 días cada 30 meses. Este mes marca el inicio de un semestre invernal y, cinco semestres después, el inicio de un semestre estival. Los treinta días del mes intercalar operan como un "recordatorio" del día correspondiente de cada uno de los treinta meses precedentes (Duval y Pinault 1986: 385-395). Este procedimiento permitía una concordancia entre el ciclo lunar y el solar en los cinco años del calendario.

El año y el lustro comenzaban el mes de Samon-, nombre semejante al del primer mes del antiguo año celta. Además, el segundo día de la segunda quincena lleva la indicación trinox samoni, "las tres noches de Samon $\rightarrow$, semejante a la fiesta irlandesa de samain a comienzos de noviembre. La dificultad está en que la palabra presenta una raíz que significa "verano" (Delamarre 2003: 267) cuya presencia en noviembre causa dificultades. La explicación es que el mes samonios recapitula o cierra el verano: en irlandés Samain se explica como samb-fhuin, el "fin del verano". En paralelo, a seis meses de distancia, el séptimo mes se denomina giamonios con un término relacionado con "invierno" y que se explicaría como el final del invierno. Lo corrobora que el mes que le sigue, Simiuisonna, es la "mitad de la primavera" (Delamarre 2003: 178-179, 274). El calendario presenta también un corte nítido entre los meses $6^{\underline{0}}$ y $7^{\circ}$ y el $12^{\circ}$ y el $1^{\circ}$ del año siguiente. Estas cesuras definen la división del año en dos semestres, uno oscuro e invernal, otro claro y veraniego, también vigente en Irlanda y Gales (Loth 1904: 125; Duval y Pinault 1986: 404-405). El dualismo preside, por tanto, la estructura del calendario celta.

Por otro lado Delpech (2010) ha estudiado el tema folclórico omnipresente en el NO ibérico de la viga, o llave, con un extremo de oro y otro de alquitrán. Su vigencia en el imaginario popular es tan grande que explica muchas violaciones de restos arqueológicos en busca de su oro. En este objeto es patente la dualidad entre un principio luminoso y valioso (el oro) y otro oscuro y pobre (el alquitrán o azufre) que se resuelve en una doble resolución dialéctica mediante la capacidad ígnea del alquitrán (o azufre) que produce luz cuando se inflama y el propio carácter de comunicador del objeto en cuyos extremos se sitúan las materias opuestas. Es importante, además, señalar que el folclore ubica esta viga en lugares precisos, muchas veces en castros, jugando diferentes versiones del motivo con temas como el tesoro escondido en las cuevas o pasajes subterráneos de los mismos castros.

Una idea fundamental distingue estas formas de dualismo de otros dualismos. Es la idea del "recuerdo" o "evocación" desde uno de los polos de la dualidad hacia el

\footnotetext{
${ }^{8}$ Prósper (2002); Luján (2006); véase además sobre el culto a los Lugoves, forma del dios Lugus, Marco (2006).
} 
otro definiendo una dialéctica entre cada elemento y su contrario. En el calendario ocurre con los nombres de los días de los meses intercalares y con los nombres de los meses ubicados en el cambio de estación, que evocan el tiempo anterior. En las leyendas sobre la viga, con la naturaleza dual del elemento ígneo y el rol de unificador de contrarios que tiene la propia viga. Pues bien, este rasgo está muy presente en nuestros paisajes duales.

En Cereixa los fuegos de la Noite dos Cepos en mitad del invierno evocan la parte cálida del año mientras que San Lourenzo, en plena canícula, es hidróforo. Correlativamente, el fuego encendido en el valle, sube, y San Lourenzo sobre la colina busca abajo el agua para que a su vez baje como lluvia. También hemos visto la conjunción de contrarios que se producía entre la culebra y la vaca en O Castro y entre los mouros y San Lourenzo en el castro homónimo enlazando la cultura del valle con el espacio liminal de los castros.

En Augas Santas la parte alta del paisaje local está dominada por el agua de las fuentes y los santos invernales, sin embargo el petroglifo de la cima está flanqueado por fuegos y la roca adyacente se utilizaba para prácticas propias de la canícula. Por el contrario, en la parte baja domina el fuego del Forno da Santa y los santos y cultos de primavera y verano, pero el agua está presente en las Pioucas. Además el Forno da Santa reproduce la unidad de contrarios a microescala ya que, como sauna, produce la síntesis entre el agua y el fuego, y como lugar del martirio de la Santa, produce una síntesis semejante entre Mariña y el Forno.

Si sobre estas relaciones espaciales subrayamos, además, que las mitades tópicas tienen unas correlaciones calendáricas semejantes, en su simplicidad, a las mitades clara y oscura del año celta, es razonable sugerir que una estructura dual de base cultural celta está en la base de los paisajes duales. Pero ahora se impone regresar al presente para comprender las transformaciones producidas entre los horizontes culturales celta y cristiano.

\section{LA CRISTIANIZACIÓN DEL PAISAJE DUAL CELTA}

Estamos ante un problema estrictamente histórico. Se trata de fechar los procesos descritos, identificar a sus protagonistas y las tensiones sociales inherentes al proceso. También es cierto que nos falta mucha información pues estudiamos lugares alejados de los centros de poder generadores de textos en la Antigüedad y en la Edad Media, y alguna de la información disponible no responde a nuestras preguntas (Pérez 2005: 410-417), pero hay otras investigaciones en curso9. A expensas de sus avances

\footnotetext{
${ }^{9}$ Un equipo de la Universidade de Vigo ha excavado el entorno de O Señoriño, en la ladera del castro de Armea y ha investigado otros aspectos del contexto arqueológico, Fernández et al en prensa; Fernández en prensa. Otro equipo de arqueólogos, formado por Celso H. Barba Seara y David Pérez López, ha re-excavado en el sector septentrional del castro las antiguas intervenciones de CondeValvís en los años 1950 y establecido una señalización. Por nuestra parte trabajamos en la prolongación del estudio llevado a cabo por R. Blanco Rotea en el Forno da Santa para identificar la estratigrafía y fases constructivas de la cripta (Blanco et al 2009). Con la incorporación del geólogo Jorge Sanjurjo de la Universidade de A Coruña, y la edafóloga Cruz Ferro, del Incipit-CSIC, trabajamos en la datación absoluta de esas fases constructivas, así como de las estructuras del entorno.
} 
podemos observar cómo la transformación del paisaje derivada de la introducción del cristianismo sigue pautas que respetan la estructura preexistente, al mismo tiempo que la revisten con una nueva semántica.

Destaca como dato básico la inversión funcional que se produce entre el centro ritual y el patrón de poblamiento entre la Antigüedad (durante el dominio romano los castros que nos interesan continuaron ocupados) y la Edad Media cristiana. En efecto, los santuarios prerromanos se diferenciaban de los lugares de habitación porque carecían de las condiciones defensivas buscadas en los poblados. Sin embargo, hemos visto cómo desde la Edad Media esos lugares se convierten en lugares de habitación mientras que los castros abandonados se convierten en residencia de los mouros o sede de ritos cristianos en momentos puntuales.

TABLA 5.-La inversión del paisaje entre la Protobistoria y la Edad Media

\begin{tabular}{|c|c|}
\hline $\begin{array}{c}\text { PROTOHISTORIA / } \\
\text { ANTIGÜEDAD }\end{array}$ & castro : hábitat permanente :: santuario : reunión ocasional \\
\hline ALTA EDAD MEDIA & castro : reunión ocasional :: santuario : hábitat permanente \\
\hline
\end{tabular}

Ahora bien, aunque esta inversión está clara en términos estructurales no podemos argumentar que fuese sencilla en términos históricos. Existe toda una dinámica social, económica e institucional detrás de ese proceso que se conoce poco a poco mediante estudios específicos. Lo que nos interesa es que al final del proceso se ha producido la inversión funcional y semántica entre los puntos relevantes de los paisajes duales identificados. También nos interesa subrayar que este cambio suscitó tensiones.

Abundan los testimonios cristianos que descalifican el culto pagano rendido en la Alta Edad Media a árboles, fuentes y rocas (Dowden 2000: 25-77), con una manifestación en Gallaecia en la obra de Martín de Braga (De correctione rusticorum: 7 y 16). Recordemos, con todo, que el culto pagano se dirigía a las divinidades que residían en esos lugares, no a los lugares mismos. También es conocido que esas cautelas no siempre fueron observadas, pues abundan los testimonios de lo contrario en toda Europa. Esto ocurre, precisamente, en los dos casos que hemos examinado.

En Cereixa el centro de culto cristiano y lugar de habitación se establece, tras el abandono de los castros, junto a un robledal de probables raíces protohistóricas. En Augas Santas ocurre lo mismo en torno a unas fuentes que probablemente eran santas antes del cristianismo. Sin salir del interior de Galicia podemos completar el recorrido en Celanova. Allí una roca situada en el patio del convento de San Salvador, levantado desde el siglo X, se cristianizó como base de un calvario y sede de milagros, pero sabemos que era un lugar de función ritual en la protohistoria en relación con el gran castro de Castromao situado a dos $\mathrm{km}$ en línea recta (García y Seoane 2011). Desde esa roca se funda el monasterio y la propia villa de Celanova.

Por lo tanto, en los paisajes que estudiamos árboles, fuentes o rocas no eran solo lugares de culto paganos sino que eran, sobre todo, parte de un espacio estructurado como paisaje. Sobre estos paisajes se implanta el cristianismo desde las ciudades como un elemento exógeno que interviene junto a otras transformaciones socio-económicas 
e institucionales. La población se asienta privilegiando el acceso fácil a las tierras agrícolas sobre las condiciones defensivas enfatizadas en el período anterior. Pero también opera el factor tradicional que suponía la costumbre de reunirse en lugares con significación religiosa: nuestros robles, fuentes o rocas. De modo que los lugares «buenos para reunirse" y para rendir culto a númenes paganos se transforman en lugares «buenos para vivir" junto con las reliquias de los santos y el recuerdo de los milagros que dan sentido cristiano a la comunidad, reunida ahora en la iglesia local. Por ello en torno a Os Carballos se instaura el culto a San Blas, en torno a las Augas Santas se instaura el culto a Santa Mariña, y en torno a la roca de Celanova se levanta el monasterio de San Salvador y ya antes había un culto dedicado a San Martín, y en todos los casos sus pobladores campesinos tienen acceso inmediato a las tierras agrícolas.

Ahora bien, esos robles, fuentes y rocas no son "supervivencias" del pasado. El término "supervivencia" tiene un aura maldita de evolucionismo decimonónico pero, sobre todo, implica una apreciación equivocada de la situación que intentamos entender. La Iglesia triunfante en la Gallaecia rural altomedieval ostenta una inequívoca hegemonía cultural e ideológica. En esta situación el pasado pagano no "sobrevive" porque en términos de lectura holística del paisaje en la larga duración carece de sentido la fórmula cuando se han transformado su semántica y función globales. Y es precisamente la dimensión religiosa la que define la radicalidad de esta transformación con la inversión estructural de lugares y funciones que hemos identificado. En este sentido parece claro que el cristianismo triunfante emprendió una "lectura" del paisaje pagano tratando de comprender los hitos que lo articulaban en las tradiciones locales para, seguidamente, plantear una "negociación" entre esas tradiciones y sus propias exigencias. En esa "negociación" lo que está en juego es el acomodo pacífico de las comunidades campesinas a las formas religiosas ahora dominantes que, desde su base urbana, se expanden hacia el campo para encontrar nuevos acólitos, espacios y rentas.

En este proceso el paisaje no "sobrevive" porque sencillamente está ahí, antes, durante y después de la cristianización en la medida que lo articulan los saberes de las comunidades campesinas que lo habitan. Y, como hemos visto, su estructura básica es estable antes y después de ese cambio cultural, al tiempo que se transforma de forma radical e irreversible la semántica de los hitos definidos por esa estructura que ya será cristiana hasta que, por alguna razón difícil de imaginar, el castro de San Lourenzo o Santa Mariña dejen de denominarse por sus nombres cristianos o, tal vez más posible, cuando mueran los últimos ancianos de esas aldeas, se dejen de practicar los ritos, como ya ocurre en Cereixa, y cuando los campesinos que queden, sometidos por la presión capitalista, dejen de ver el lugar en el que viven como un depósito de saber para concebirlo en términos de explotación y rentabilidad.

De esta forma hemos cerrado el bucle de nuestro argumento. Partiendo de los relatos y prácticas de las comunidades campesinas de dos pequeños enclaves de Galicia hemos identificado unos "paisajes duales". Como los hitos que los definen son entidades arqueológicas o naturales marcadas simbólicamente, hubo que rastrear su génesis en los indicios de pensamiento dualista de tradición celta. Ahora bien, mientras que para la dimensión cristiana conocemos la semántica de esos lugares, para la situación anterior debemos conformarnos con la identificación de esa estructura vacía o, tal vez mejor, rellenada de una forma que ha desaparecido. El punto final ha consistido en intentar entender el paso de esa estructura vacía para nosotros, pero no para sus usua- 
rios originales, a su revestimiento cristiano. En particular hemos mostrado que el cristianismo transforma el mundo rural de Galicia de forma sistémica y reflexiva, y que su éxito, marcado por su permanencia temporal, nos ha abierto la puerta a este estudio.

\section{CODA}

Un revisor del presente artículo señala el contraste entre la intención explicativa del texto y la muestra usada de solo dos casos. Tiene razón. Teníamos que elegir entre introducir más casos con un tratamiento somero y discutible o ceñirnos a dos mejor argumentados para sostener una propuesta de cierto alcance teórico en el espacio de un artículo, que es la opción seguida. Otros trabajos en prensa o en preparación intentarán subsanar esta carencia. En García et al (2015) nos centramos en las relaciones astronómicas del par topológico castro-santuario en la Edad del Hierro y cómo se cristianiza, allí introducimos análisis complementarios sobre Santa Mariña de Augas Santas, junto con otros dos casos en la provincia de Ourense. En Belmonte et al (2013) se expone una estructura semejante en Campo Lameiro (Pontevedra): sobre un paisaje arqueológico de grabados rupestres se aprecia cómo la romanización y posterior cristianización mantienen una estructura dual. El argumento de un libro en preparación sobre el mito de fundación de Lugdunum (Lyon, Francia) trata sobre cómo la dialéctica dual céltica adopta formas materiales romanas y se fija en el paisaje, siendo las formas de esa mutación romana el equivalente de las mutaciones cristianas que hemos estudiado aquí (véase parcialmente García 2008; García y González 2015). Tenemos en agenda otros posibles lugares donde aplicar estos análisis, pero también es preciso señalar que para construir la información de base es necesario un esfuerzo prolongado en el tiempo por parte de especialistas con capacidades complementarias, ellos son los compañeros con los que firmo los trabajos en colaboración que he citado y otros en curso de elaboración. También es pertinente indicar que la naturaleza de la información con la que podemos trabajar nos lleva a publicar en revistas muy diferentes ${ }^{10}$.

\section{BIBLIOGRAFÍA CITADA}

Arizaga, Á. y Ayán, X. M. 2007. "Etnoarqueología del paisaje castreño: la segunda vida de los castros", en González García, F. J. (ed.), Los pueblos de la Galicia Céltica: 445-531. Madrid: Akal.

Ayán Vila, X. M. 2005. "Etnoarqueoloxía e microhistoria dunha paisaxe cultural: a parroquia de S. Pedro de Cereixa (Pobra de Brollón, Lugo)". Cuadernos de Estudios Gallegos 52: 117-172.

Bader, F. 1966. "Forets et arbres du domaine indo-européen", en Actes du colloque sur la foret: 2130. Besançon: Université de Franche-Comté.

Barandela Rivero, I. y Lorenzo Rodríguez, J. M. 2011. "El culto a Santa Mariña en el norte de la Península Ibérica y sus conexiones con la Europa Atlántica". Porta da Aira 13: 117-143.

Belmonte Avilés, J. A., García Quintela, M. V. y González García, A. C. 2013. "Ciervos, tiempo y paisaje: una integración arqueoastronómica", en Criado Boado, F., Martínez Cortizas, A. y García Quintela, M. V. (eds.), Petroglifos, paleoambiente y paisaje. Estudios interdisciplinares del arte rupestre de Campo Lameiro: 197-210. Madrid: CSIC.

${ }^{10}$ Los resultados de estas investigaciones se publicarán a medida que aparezcan en https:// usc-es.academia.edu/marcogarcia 
Berque, A. 2009. El Pensamiento paisajero. Madrid: Biblioteca Nueva.

Blair, J. 2005. The church in Anglo-Saxon society. Oxford: Oxford University Press.

Blanco Rotea, R., Mañana Borrazás, P., Mato Fresán, C. y Rodríguez Costas, A. 2009. "La Basílica de la Ascensión y Os Fornos (Allariz, Ourense)". Revista Aquae Flaviae 41: 467-477.

Bouza Brey, F. 1982. Etnografia y Folklore de Galicia (1). Vigo: Xerais.

Braudel, F. 1958. "Histoire et Sciences sociales : La longue durée». Annales ESC 13: 725-753.

Briquel, D. 1980. "Trois études sur Romulus", en Bloch, R. (ed.), Recherches sur les religions de l'Antiquité classique: 267-346. Ginebra: Droz.

Brown, P. 1983. The cult of the saints. Londres: SCM.

Collis, J. 2003. Celts: origins, myths and inventions. Stroud: Tempus.

Criado Boado, F. 1986. "Serpientes gallegas: madres contra rameras", en Mitología y mitos de la Hispania prerromana 2: 241-274. Madrid: Akal.

Criado Boado, F. 2012. Arqueológicas, la razón perdida: la construcción de la inteligencia arqueológica. Barcelona: Bellaterra.

De Bernardo, P. y García Quintela, M. V. 2008. "Población trilingüe y divinidades del castro de Lansbriga (NO de España)". Madrider Mitteilungen 49: 254-290.

De la Cueva, B. 1991. Historia de los monasterios y prioratos anejos a Celanova (ed de Mª T. González Balasch). Granada: Universidad.

Delamarre, X. 2003. Dictionnaire de la langue gauloise. París: Errance.

Delgado Gómez, J. 1984. "La Biblia en la iconografía pétrea lucense. 4. El Crismón de Quiroga". Boletín do Museo Provincial de Lugo 11: 85-105.

Delpech, F. 2010. "Le trésor et la clef : de la mythologie celtique au folklore de l'or caché dans les traditions ibériques", en Burillo Mozota, F. (ed.), VI Simposio sobre celtíberos. Ritos y Mitos: 523540. Daroca y Zaragoza: Centro de Estudios Darocenses y Fundación Fernando el Católico.

Díaz, P. C. 2011. El Reino Suevo (411-585). Madrid: Akal.

Dowden, K. 2000. European Paganism. Londres: Routledge.

Duval, P. M. y Pinault, G. 1986. Recueil des inscriptions Gauloises (RIG). III. Les Calendriers (Coligny, Villards d'Heria). París: CNRS.

Fariña Busto, F. 2002. Santa Mariña de Augas Santas. Ourense: Fundación Caixa Galicia.

Fernández Fernández, A. en prensa. "Las excavaciones en el monte do Señoriño: redescubriendo el conjunto arqueológico de Armea - Sta. Mariña de Augas Santas (Allariz, Ourense)", en Simpósio internacional sociedade, cultura e economia nas regioes serranas da Hispânia romana, Guarda, setembro 2013.

Fernández Fernández, A., Casal Fernández, L., Valle Abad, P. y Vázquez Fernández, L. en prensa. "La cerámica galaico-romana de Armea (Allariz). Monte do Señoriño y Castro de Armea", en $A c$ tas del II ${ }^{\circ}$ Congreso Internacional de la Sociedad de Estudios de la Cerámica Antigua en Hispania, Braga, abril de 2013.

FitzPatrick, E. 2004. Royal Inauguration in Gaelic Ireland c. 1100-1600. Woodbridge: Boydell.

Foucault, M. 1970. La arqueología del saber. Madrid: Siglo XXI.

García Alonso, J. L. 2006. "Briga toponyms in the Iberian Peninsula". e-Keltoi 6: The Celts in the Iberian Peninsula.

García García, F. de A. 2010. "El Crismón”. Revista Digital de Iconografía Medieval 2: 21-31.

García Quintela, M. V. 2011a. "El mito de fundación de Lugdunum: ensayo de lectura estructural", en Meurant, A. (ed.), Routes et parcours mythiques: des textes à l'archéologie: 115-138. Bruselas: Safran.

García Quintela, M. V. 2011b. "Topologías comparadas de la Antigüedad", https://www.academia.edu/ 1718338/Topologias_Comparadas_de_la_Antiguedad

García Quintela, M. V. 2013. "Sobre lugares y discursos: antropología de la topología comparada", en Criado Boado, F., Martínez Cortizas, A. y García Quintela, M. V. (eds.), Petroglifos, paleoambiente y paisaje. Estudios interdisciplinares del arte rupestre de Campo Lameiro: 211-224. Madrid: CSIC.

García Quintela, M. V. y Delpech, F. 2013. El Árbol de Guernica. Madrid: Abada.

García Quintela, M. V. y González García, A. C. 2009. "Arqueoastronomía, Antropología y Paisaje". Complutum 20: 39-54.

García Quintela, M.V. y González García, A. C. 2015 "Le 1 ${ }^{\text {er }}$ août à Lugdunum sous l'Empire Romain : bilans et nouvelles perspectives ". Revue Archaeologique de l'Est (en prensa). 
García Quintela, M. V., González García, A. C. y Seoane-Veiga, Y. 2015. "De los solsticios en los castros a los santos cristianos: la creación del paisaje cristiano en Galicia". Madrider Mitteilungen (en prensa).

García Quintela, M. V. y Santos Estévez., M. 2008. Santuarios de la Galicia Céltica. Madrid: Abada.

García Quintela, M. V. y Seoane-Veiga, Y. 2011. "La Larga Vida de dos rocas ourensanas". Archivo Español de Arqueología 84: 241-264.

García Quintela, M. V. y Seoane Veiga, Y. 2015. "Entre naturaleza y cultura. Arquitectura ambigua en la Edad del Hierro del NO peninsular". Gallaecia, en prensa.

González García, F. J. 2011. "Los Célticos de Gallaecia: apuntes sobre etnicidad y territorialidad en la Edad del Hierro del Noroeste de la Península Ibérica". Complutum 22: 117-132.

Guerra, A. 2005. "Povos, cultura e língua no ocidente peninsular: uma perspectiva, a partir da toponomástica". Palaeohispanica 5: 793-822.

Ingold, T. 2000. The perception of the Environment. Londres: Routledge.

Loraux, N. 1984. Les enfants d'Athéna. París: La Dècouverte.

Loth, J. 1904. "L'Année celtique d'après les textes irlandais, gallois, bretons, et le calendrier de Coligny". Revue Celtique 25: 113-162.

Luján, E. R. 2006. "The Language(s) of the Callaeci". e-Keltoi 6: The Celts in the Iberian Peninsula.

Luján, E. R. 2009. "Pueblos celtas y no celtas de la Galicia Antigua: fuentes literarias frente a fuentes epigráficas", en XXII Seminario de Lenguas y Epigrafia Antiguas: 219-250. Valencia: Real Acadèmia de Cultura Valenciana.

MacNeill, M. 1962. The festival of Lugnasa. Oxford: Oxford University Press.

Maderuelo, J. 2005. El paisaje. Madrid: Abada.

Madoz, P. 1848. Diccionario Geográfico-Estadístico-Histórico de España I. Madrid: Imprenta del Diccionario Geográfico-Estadístico-Histórico de D. Pascual Madoz.

Madoz, P. 1849. Diccionario Geográfico-Estadístico-Histórico de España V. Madrid: Imprenta del Diccionario Geográfico-Estadístico-Histórico de D. Pascual Madoz.

Marco Simón, F. 2006. "The cult of the Lugoves in Hispania". Acta Archaeologica Academiae Scientiarum Hungarica 57: 403-486.

Molina, S. de (Licenciado Molina) 1551. Descripcion del Reyno de Galizia. Mondoñedo: Agustín Paz.

Moralejo, J. J. 2008. Callaica Nomina. A Coruña: Fundación Pedro Barrié de la Maza.

Morales, A. de 1574. La Coronica general de España. Alcalá de Henares: en casa de Iuan Iñiguez de Lequerica.

Muñoz de la Cueva, J. 1719: Breve compendio de la vida y martyrio de la Gloriosa Virgen y Martyr Sta. Marina. A Coruña: Orbigo (reimpresión facs. 2005).

Pérez Rodríguez, F. J. 2005. "As abadías seglares do bispado de Ourense na Idade Media (Séculos XII-XV)", en Homaxe á profesora Lola F. Ferro: 401-442. Ourense.

Prósper, B. M. 2002. Lenguas y religiones prerromanas del Occidente de la Península Ibérica. Salamanca: Universidad.

Sánchez Pardo, J. C. 2009. "Sobre los orígenes y evolución de las primeras iglesias rurales en la Alta Edad Media: el caso de Terra de Celanova (Ouense)". Revista Aquae Flaviae 41: 433-445.

Sánchez Pardo, J. C. 2010. "Castros y aldeas Galaicoromanas: sobre la evolución y transformación del poblamiento indígena en la Galicia Romana". Zephyrus 65: 129-148.

Schot, R. 2006. "Uisneach Midi a medón Érenn: a prehistoric 'cult' centre and 'royal site' in Co. Westmeath". Journal of Irish Archaeology 15: 39-71.

Seoane Veiga, Y. 2011. Avaliación do patrimonio cultural nas áreas afectadas polos incendios forestais do ano 2006: Campo Lameiro e Cotobade. Santiago: CSIC.

Sherlock, W. 1896. Some account of St. Brigid and of the see of Kildare. Dublín: Hodges, Figgis \& Co. Sterckx, C. 2009. Mythologie du monde celte. París: Marabout.

Tuan, Y.-F. 1997. Space and place: the perspective of experience. Minneapolis: University of Minnesota Press. Yates, F. 1999. The art of memory. Londres: Routledge.

Fecha de recepción: 20 de junio de 2013

Fecha de aprobación: 18 de marzo de 2014 